\title{
A Review of Three New Anti-interleukin-5 Monoclonal Antibody Therapies for Severe Asthma
} Vivian C. Agumadu ${ }^{1}$, Kamleshun Ramphul ${ }^{2}$, Stephanie G. Mejias ${ }^{3}$, Ruhi Sonaye ${ }^{4}$, Shaheen Sombans ${ }^{5}$,
Petras Lohana ${ }^{6}$

1. Medicine, International University of the Health Sciences School of Medicine, Basseterre, KNA 2. Pediatrics, Shanghai Jiao Tong University School of Medicine/Shanghai Xin Hua Hospital, Shanghai, CHN 3. Pediatrics, The University Iberoamericana Unibe School of Medicine/Robert Reid Cabral Children's Hospital, Santo Domingo, DOM 4. Bharati Vidyapeeth Deemed University Medical College and Hospital, Thane, IND 5. Internal Medicine, Bharati Vidyapeeth Deemed University Medical College and Hospital, Pune, IND 6. Medicine, Liaquat University of Medical and Health Sciences Hospital, Karachi, PAK

Corresponding author: Kamleshun Ramphul, adramphul@hotmail.com

\begin{abstract}
Asthma is a chronic respiratory condition that is characterized by reversible airflow obstruction. Interleukin5 (IL-5) is involved in the pathophysiology of the disease and drugs targeting IL-5 have been studied for years as a possible treatment option for severe asthma. In this review, the authors searched PubMed for major drug therapies and clinical trials against IL-5. A total of 29 articles met the criteria for selection and were shortlisted; of these, 10 papers were on benralizumab, 14 on mepolizumab, and five on reslizumab.

The three drugs proved to be safe and efficacious for patients with severe asthma, leading to decreased rates of asthma exacerbations, lowered levels of eosinophils, and improved pulmonary functions in various studies. Patients also reported an improvement in the quality of life. The side effects of these three drugs were mild and no deaths directly linked to the drug were reported. However, longer duration studies are required to draw firm and strong conclusions on the safety of these therapeutic agents.
\end{abstract}

Received 08/16/2018

Review began 08/16/2018 Review ended 08/26/2018 Published 08/27/2018

\section{() Copyright 2018}

Agumadu et al. This is an open access article distributed under the terms of the Creative Commons Attribution License CC-BY 3.0., which permits unrestricted use, distribution, and reproduction in any medium, provided the original author and source are credited.
Categories: Internal Medicine, Allergy/Immunology

Keywords: monoclonal antibody, asthma

\section{Introduction And Background}

Asthma is a chronic respiratory condition that is characterized by reversible airflow obstruction. There are a number of environmental and genetic factors associated with the development of the condition. It causes a significant economic burden on society, affecting more than 334 million people worldwide. Asthma is estimated to cause 250,000 deaths annually and consumes billions of dollars in treatment. The global impact of asthma and the prevalence of the disease is constantly increasing [1].

Treatment plans for asthma vary according to the severity of the condition and the response to previous therapy. The aim is to achieve control and prevent future exacerbations of the disease. The treatment of choice for mild cases of asthma and for intermittent asthma involves treatment with a short-acting beta agonist such as albuterol. If the asthma is persistent, the physician may choose to alter the treatment options in a stepwise manner by adding low dose inhaled corticosteroids (ICS). The doses of ICS can be further increased depending on the severity and failure to show any signs of improvement by the patients. Other treatment options include the use of leukotriene receptor antagonists (LTRAs) such as montelukast or zafirlukast. The use of theophylline or zileuton may also be considered. Montelukast is also a treatment option for exercise-induced asthma and has been approved for use in children as young as one year of age while zafirlukast can be used in children up to the age of seven. For cases of steroid-resistant asthma, omalizumab is also a possible treatment option [2].

Severe asthma is classified as asthma with symptoms that persist and are uncontrolled despite a high dose of ICS and a second controller and/or systemic corticosteroids [3]. An estimated 5\%-10\% of asthma patients are classified as severe asthma while recent data suggests that the number might be lower than five percent [4]. Two-thirds of patients with severe asthma suffer from late-onset asthma with a higher female to male ratio [5]. Uncontrolled asthma presents with at least one of the following: frequent severe exacerbations, serious exacerbations, or airflow limitation with persistent low forced expiratory volume in one second (FEV1) after appropriate bronchodilation and/or poor symptom control [6].

Since the pathophysiology of asthma involves multiple immunological cells and cytokines, recent therapeutic advances over the past three decades focused on identifying anti-cytokine and monoclonal antibody therapies. Eosinophils can release their pro-inflammatory mediators, such as major basic proteins, cytokines, and chemokines that potentiate the lung injury. Interleukin-5, which is derived from type two 
helper cells (TH2), plays a major role in the development and release of eosinophils. It has been considered as one of the therapeutic targets for preventing and treating asthma [7-8]. The aim of this review is to provide a concise discussion of the various monoclonal therapies against IL-5 that are available for the treatment of asthma.

\section{Review}

\section{Methods}

The authors searched PubMed to identify major drug therapies and clinical trials against IL-5. The search was restricted to articles published from the first of January 2000 to the first of May 2018. The results were further limited to articles published in English. Studies were independently reviewed by each author prior to preparing a pooled analysis.

\section{Results}

The authors found 29 articles of interest; of these, 10 papers were on benralizumab, 14 on mepolizumab, and five on reslizumab. The selection was limited to clinical studies published in English and investigating primarily the changes in clinical presentations of patients with severe asthma and/or eosinophil levels. We further discussed any difference in statistical significance in the results that were found among the selected studies in the review.

\section{Discussion}

The authors focused on three main therapies against IL-5 that have undergone several clinical trials. A brief understanding of the roles of IL-5 and eosinophils in the pathophysiology of asthma was also discussed below.

Pathophysiology of Asthma, IL-5, and Eosinophils

Eosinophils are granulocytes that form one to four percent of circulating white cell count. In a normal homeostatic state, almost all eosinophils are found in tissues after they have been released by the CD34+ progenitor cells in the bone marrow [9]. They contain several granules containing major basic protein (MBP), eosinophil-derived neurotoxin (EDN), eosinophil cationic protein (ECP), and eosinophil peroxidase (EPO). When eosinophils are activated, they mediate cellular injury by releasing the contents of these granules. Eosinophils can also release several cytokines, reactive oxygen species, chemokines, and lipid mediators that are pro-inflammatory. During an eosinophilic asthma attack, there is an increased production of eosinophils by the bone marrow. These cells migrate to the airways and once activated, they start secreting the content of their granules [10]. This leads to damage to the smooth muscles of the airways resulting in bronchoconstriction [11]. Eosinophils are also involved in the remodeling of airways. In vivo studies have shown that they can influence the activity of fibroblasts [12]. Bousquet et al. even reported that the levels of eosinophils in blood and bronchoalveolar lavage are associated with the severity of asthma [10]. Levels of eosinophils usually improve after an asthma attack and several studies have proved that the long-term use of glucocorticoids can help lower the level of eosinophils [13].

Interleukin-5 plays an important role in the formation of eosinophils in the bone marrow, as well as in their maturation, migration, and activation. IL-5 also inhibits apoptosis, thus promoting the survival of eosinophils $[9,14]$. Some studies have suggested that Eotaxin, a chemokine, has a dose-dependent capacity to stimulate eosinophil production by progenitor cells in the bone marrow and the role of eotaxin was independent of IL-5 [15]. However, Foster et al. and Tanaka et al. have also proved that the inhibition of IL-5 or using animals that are deficient in IL-5 receptors can lead to a lower level of eosinophils and less severe remodeling in animals with asthma [16-17]. In humans, the inhalation of IL-5 led to airway hyperreactivity and eosinophilia in asthmatics [18].

Mepolizumab

Mepolizumab is a humanized monoclonal antibody that works against interleukin-5. It is used for the treatment of severe eosinophilic asthma and has been approved for clinical use since 2015. In a study conducted by Bel et al., treatment with mepolizumab lowered the glucocorticoid dose required for severe eosinophilic asthma and the reduction was 2.39 times higher with mepolizumab than with the placebo [19]. In another study by Nair et al., $750 \mathrm{mg}$ mepolizumab each month for five months lowered the prednisone dose by a mean of $83.8 \pm 33.4 \%$ of their maximum possible dose, as compared with $47.7 \pm 40.5 \%$ in the placebo group [20]. The drug can decrease the yearly exacerbation rate of asthma (47\% and 53\% lower with $250 \mathrm{mg}$ intravenous and $250 \mathrm{mg}$ subcutaneous mepolizumab respectively) [21-22] and improve the forced expiratory volume in one second (FEV1) (mean increase of $100 \mathrm{~mL}$ with $75 \mathrm{mg}$ intravenous mepolizumab and $98 \mathrm{~mL}$ with 100 mg subcutaneous mepolizumab) [20,23-24] and peak expiratory flow (PEF) [25]. With the proper inhibition of IL-5, this drug can cause a decrease in the sputum and blood eosinophil count [20,24-30], which can be dose-dependent [31]. Mepolizumab has shown its role in improving the quality of life of asthmatics with an improved Asthma Control Questionnaire (ACQ) and St. George's Respiratory 
Questionnaire (SGRQ) score [23]. While some studies have shown that the route of administration had no effect on the exposure-response relationship [31], Ortega et al. found that intravenous mepolizumab lowered the rate of exacerbation by $47 \%$ while it was $53 \%$ lower via the subcutaneous route when compared with the placebo [23]. Mepolizumab also reduced airway eosinophils and decreased the expression of lumican, tenascin, and procollagen III in the bronchial mucosal reticular basement membrane. Tissue remodeling was slowed with an inhibition of eosinophilic expression of transforming growth factor beta one (TGF- $\beta 1$ ) [28].

There are multiple adverse effects associated with mepolizumab use but with a low incidence. The most common ones are asthma exacerbation, nasopharyngitis, headache, diarrhea, constipation, eczema, bronchitis, oropharyngeal pain, malaise, migraine, upper respiratory tract infections (URTI), and injection site reactions [19,23-25,27,31-32].

Reslizumab

Reslizumab is a humanized anti-IL-5 monoclonal antibody. The drug binds to circulating IL-5 with high affinity, thus preventing it from binding to IL-5 receptors [33]. Recent clinical trials have shown that a three $\mathrm{mg} / \mathrm{kg}$ dose of reslizumab given intravenously has a good long-term safety and efficacy, with patients suffering from moderate-to-severe eosinophilic asthma [34]. The pulmonary functions improved in the study (0.090L at week 16 in the reslizumab-naive group, $\mathrm{p}<0.0001$ ) and the patients had proper asthma control over the course of the study. Another study by Bjermer et al. demonstrated an improvement in mean FEV1 $(115 \mathrm{~mL}$ with a dose of $0.3 \mathrm{mg} / \mathrm{kg}$ and $160 \mathrm{~mL}$ with three $\mathrm{mg} / \mathrm{kg})$, forced vital capacity (FVC) (130mL with three $\mathrm{mg} / \mathrm{kg}$ ), forced expiratory flow at $25 \%-75 \%$ of the pulmonary volume (FEF $25 \%-75 \%$ ) (233 mL with three $\mathrm{mg} / \mathrm{kg}$ ) as well as ACQ and Asthma Quality of Life Questionnaire (AQLQ) scores. The patients also had better asthma Symptom Utility Index scores [35]. These findings were supported by other clinical trials, such as the study by Castro et al., which reported that their patients showed mean changes in the ACQ score of 0.7 in the reslizumab group as compared to -0.3 in the placebo group. Their mean changes in FEV1 were also 0.18 and $-0.08 \mathrm{~L}$, respectively. Median reductions from the baseline in sputum eosinophils were $95.4 \%$ and $38.7 \%$, respectively, in their study [36]. Another study by the same group showed a reduction in the rate of asthma exacerbations with reslizumab therapy over 52 weeks [37]. In a study by Corren et al., a better improvement in FEV1, ACQ (seven), rescue short-acting beta agonists (SABA) use, and FVC were seen when Reslizumab was used in patients with a baseline eosinophil count of $\geqslant 400$ cells $/ \mu \mathrm{L}$. Patients with a lower eosinophil count showed non-significant changes with the drug in that study [38].

There was no mortality reported linked directly to the use of the drug. The most common adverse effects were asthma, upper respiratory tract infection, sinusitis, bronchitis, and nasopharyngitis.

Benralizumab

Benralizumab is an afucosylated, humanized, monoclonal antibody against the IL-5 receptor alpha that is found on the surface of basophils and eosinophils [39-40]. The drug can help lower the annual exacerbation rates [41-47] and improve the total asthma symptom score [41,46]. However, in smaller doses of two mg, in one study, it decreased the exacerbation by 33\% [45], while in another study, it did not cause any significant change [43]. Studies have also shown an improvement in FEV1 when given at $30 \mathrm{mg}$ for 56 weeks [41], 52 weeks [45], 48 weeks [46], and 12 weeks [48] while Nair et al. failed to find any improvement with the same dose over 28 weeks [47]. The drug also led to lower mucosal, sputum, and blood eosinophil counts [44,49-50]. Nair et al. showed that the use of $30 \mathrm{mg}$ of benralizumab over 28 weeks resulted in a significant reduction in oral glucocorticoid doses as well as an improvement of symptoms and exacerbations. Pham et al. noted that with an IL-5 receptor alpha inhibitor like benralizumab, serum IL-5, eotaxin/ CCL11, and eotaxin-2/CCL24 levels were higher compared to placebo [50].

The main side effects associated with benralizumab included nasopharyngitis, injection site reaction, upper respiratory tract infection, and worsening asthma. A small portion of patients in a study conducted by Nowak et al. also experienced pyrexia, tachycardia, and anxiety.

\section{Conclusions}

Over the last two decades, the pharmacological world has taken great initiatives to find new and safer drugs with good efficacy. Mepolizumab was the first monoclonal antibody against IL-5 approved for use in 2015. Many clinical trials have been conducted for new drugs, and reslizumab also gained approval by the Food and Drug Administration (FDA) in 2016 and benralizumab in 2017. This review found that, at present, with the reported clinical trials, there are no major adverse effects that led to any mortality directly caused by these three monoclonal antibodies. However, these drugs have been clinically used for a short period of time and longer follow-ups should be performed to monitor for any more serious adverse effects. At present, prudence should be maintained when using these therapies and any major adverse effects should be reported.

\section{Additional Information}




\section{Disclosures}

Conflicts of interest: In compliance with the ICMJE uniform disclosure form, all authors declare the following: Payment/services info: All authors have declared that no financial support was received from any organization for the submitted work. Financial relationships: All authors have declared that they have no financial relationships at present or within the previous three years with any organizations that might have an interest in the submitted work. Other relationships: All authors have declared that there are no other relationships or activities that could appear to have influenced the submitted work.

\section{References}

1. Accordini S, Corsico A, Cerveri I, et al.: The socio-economic burden of asthma is substantial in Europe . Allergy. 2008, 63:116-124. 10.1111/j.1398-9995.2007.01523.x

2. Guidelines for the diagnosis and management of Asthma (EPR-3) . (2004). Accessed: August 20, 2018: https://www.nhlbi.nih.gov/health-topics/guidelines-for-diagnosis-management-of-asthma.

3. Chung KF, Wenzel SE, Brozek JL, et al.: International ERS/ATS guidelines on definition, evaluation and treatment of severe asthma. Eur Respir J. 2014, 43:343-373. 10.1183/09031936.00202013

4. Hekking PP, Wener RR, Amelink M, Zwinderman AH, Bouvy ML, Bel EH: The prevalence of severe refractory asthma. J Allergy Clin Immunol. 2015, 135:896-902. 10.1016/j.jaci.2014.08.042

5. Bobolea I, Barranco P, Del Pozo V, et al.: Sputum periostin in patients with different severe asthma phenotypes. Allergy. 2015, 70:540-546. 10.1111/all.12580

6. Korn S, Both J, Jung M, Hubner M, Taube C, Buhl R: Prospective evaluation of current asthma control using ACQ and ACT compared with GINA criteria. Ann Allergy Asthma Immunol. 2011, 107:474-479. 10.1016/j.anai.2011.09.001

7. Walsh GM: Advances in the immunobiology of eosinophils and their role in disease. Critical reviews in clinical laboratory sciences. Crit Rev Clin Lab Sci. 1999, 36:453-496. 10.1080/10408369991239277

8. O'Byrne PM: The demise of anti IL-5 for asthma, or not . Am J Respir Crit Care Med. 2007, 176:1059-1060. 10.1164/rccm.200708-1264ED

9. Rosenberg HF, Phipps S, Foster PS: Eosinophil trafficking in allergy and asthma. J Allergy Clin Immunol. 2007, 119:1302-1303. 10.1016/j.jaci.2007.03.048

10. Bousquet J, Chanez P, Lacoste JY, et al.: Eosinophilic inflammation in asthma. N Engl J Med. 1990, 323:1033-1039. 10.1056/NEJM199010113231505

11. Oddera S, Silvestri M, Balbo A, Jovovich BO, Penna R, Crimi E, Rossi GA: Airway eosinophilic inflammation, epithelial damage, and bronchial hyperresponsiveness in patients with mild-moderate, stable asthma. Allergy. 1996, 51:100-107. 10.1111/j.1398-9995.1996.tb04565.x

12. Hernnas J, Sarnstrand B, Lindroth P, Peterson CG, Venge P, Malmstrom A: Eosinophil cationic protein alters proteoglycan metabolism in human lung fibroblast cultures. Eur J Cell Biol. 1992, 59:352-363.

13. Chlumsky J, Striz I, Terl M, Vondracek J: Strategy aimed at reduction of sputum eosinophils decreases exacerbation rate in patients with asthma. J Int Med Res. 2006, 34:129-139. 10.1177/147323000603400202

14. Takatsu K: Interleukin-5 and IL-5 receptor in health and diseases . Proc Jpn Acad Ser B Phys Biol Sci. 2011, 87:463-485. 10.2183/pjab.87.463

15. Lamkhioued B, Abdelilah SG, Hamid Q, Mansour N, Delespesse G, Renzi PM: The CCR3 receptor is involved in eosinophil differentiation and is up-regulated by Th2 cytokines in CD34+ progenitor cells. J Immunol. 2003, 170:537-547. 10.4049/jimmunol.170.1.537

16. Tanaka H, Komai M, Nagao K, et al.: Role of interleukin-5 and eosinophils in allergen-induced airway remodeling in mice. Am J Respir Cell Mol Biol. 2004, 31:62-68. 10.1165/rcmb.2003-0305OC

17. Foster PS, Hogan SP, Ramsay AJ, Matthaei KI, Young IG: Interleukin 5 deficiency abolishes eosinophilia, airways hyperreactivity, and lung damage in a mouse asthma model. J Exp Med. 1996, 183:195-201. 10.1084/jem.183.1.195

18. Shi HZ, Xiao CQ, Zhong D, et al.: Effect of inhaled interleukin-5 on airway hyperreactivity and eosinophilia in asthmatics. Am J Respir Crit Care Med. 1998, 157:204-209. 10.1164/ajrccm.157.1.9703027

19. Bel EH, Wenzel SE, Thompson PJ, et al.: Oral glucocorticoid-sparing effect of mepolizumab in eosinophilic asthma. N Engl J Med. 2014, 371:1189-1197. 10.1056/NEJMoa1403291

20. Nair P, Pizzichini MMM, Kjarsgaard M, et al.: Mepolizumab for prednisone-dependent asthma with sputum eosinophilia. N Engl J Med. 2009, 360:985-993. 10.1056/NEJMoa0805435

21. Ortega HG, Yancey SW, Mayer B, et al.: Severe eosinophilic asthma treated with mepolizumab stratified by baseline eosinophil thresholds: a secondary analysis of the DREAM and MENSA studies. Lancet Respir Med. 2016, 4:549-556. 10.1016/S2213-2600(16)30031-5

22. Lugogo N, Domingo C, Chanez P, et al.: Long-term efficacy and safety of mepolizumab in patients with severe eosinophilic asthma: a multi-center, open-label, phase IIIb study. Clin Ther. 2016, 38:2058-2070. 10.1016/j.clinthera.2016.07.010

23. Ortega HG, Liu MC, Pavord ID, et al.: Mepolizumab treatment in patients with severe eosinophilic asthma . N Engl J Med. 2014, 371:1198-1207. 10.1056/NEJMoa1403290

24. Haldar P, Brightling CE, Singapuri A, et al.: Outcomes after cessation of mepolizumab therapy in severe eosinophilic asthma: a 12-month follow-up analysis. J Allergy Clin Immunol. 2014, 133:921-923. 10.1016/j.jaci.2013.11.026

25. Shimoda T, Odajima H, Okamasa A, et al.: Efficacy and safety of mepolizumab in Japanese patients with severe eosinophilic asthma. Allergol Int. 2017, 66:445-451. 10.1016/j.alit.2016.11.006

26. Flood-Page P, Swenson C, Faiferman I, et al.: A study to evaluate safety and efficacy of mepolizumab in patients with moderate persistent asthma. Am J Respir Crit Care Med. 2007, 176:1062-1071. 10.1164/rccm.200701-0850C

27. Tsukamoto N, Takahashi N, Itoh H, Pouliquen I: Pharmacokinetics and pharmacodynamics of mepolizumab, an anti-interleukin 5 monoclonal antibody, in healthy Japanese male subjects. Clin Pharmacol Drug Dev. 2016, 5:102-108. 10.1002/cpdd.205 
28. Flood-Page P, Menzies-Gow A, Phipps S, et al.: Anti-IL-5 treatment reduces deposition of ECM proteins in the bronchial subepithelial basement membrane of mild atopic asthmatics. J Clin Invest. 2003, 112:10291036. 10.1172/jci17974

29. Flood-Page PT, Menzies-Gow AN, Kay AB, Robinson DS: Eosinophil's role remains uncertain as antiinterleukin-5 only partially depletes numbers in asthmatic airway. Am J Respir Crit Care Med. 2003, 167:199-204. 10.1164/rccm.200208-7890C

30. Buttner C, Lun A, Splettstoesser T, Kunkel G, Renz H: Monoclonal anti-interleukin-5 treatment suppresses eosinophil but not T-cell functions. Eur Respir J. 2003, 21:799-803. 10.1183/09031936.03.00027302

31. Pouliquen IJ, Kornmann O, Barton SV, Price JA, Ortega HG: Characterization of the relationship between dose and blood eosinophil response following subcutaneous administration of mepolizumab. Int J Clin Pharmacol Ther. 2015, 53:1015-1027. 10.5414/cp202446

32. Pavord ID, Korn S, Howarth P, et al.: Mepolizumab for severe eosinophilic asthma (DREAM): a multicentre, double-blind, placebo-controlled trial. Lancet. 2012, 380:651-659. 10.1016/s0140-6736(12)60988-x

33. Egan RW, Athwal D, Bodmer MW, et al.: Effect of Sch 55700, a humanized monoclonal antibody to human interleukin-5, on eosinophilic responses and bronchial hyperreactivity [Article in English, German]. Arzneimittelforschung. 1999, 49:779-790. 10.1055/s-0031-1300502

34. Murphy K, Jacobs J, Bjermer L, et al.: Long-term safety and efficacy of reslizumab in patients with eosinophilic asthma. J Allergy Clin Immunol Pract. 2017, 5:1572-1581. 10.1016/j.jaip.2017.08.024

35. Bjermer L, Lemiere C, Maspero J, Weiss S, Zangrilli J, Germinaro M: Reslizumab for inadequately controlled asthma with elevated blood eosinophil levels: a randomized phase 3 study. Chest. 2016, 150:789-798. 10.1016/j.chest.2016.03.032

36. Castro M, Mathur S, Hargreave F, et al.: Reslizumab for poorly controlled, eosinophilic asthma: a randomized, placebo-controlled study. Am J Respir Crit Care Med. 2011, 184:1125-1132. 10.1164/rccm.201103-03960C

37. Castro M, Zangrilli J, Wechsler ME, et al.: Reslizumab for inadequately controlled asthma with elevated blood eosinophil counts: results from two multicentre, parallel, double-blind, randomised, placebocontrolled, phase 3 trials. Lancet Respir Med. 2015, 3:355-366. 10.1016/\$2213-2600(15)00042-9

38. Corren J, Weinstein S, Janka L, Zangrilli J, Garin M: Phase 3 study of reslizumab in patients with poorly controlled asthma: effects across a broad range of eosinophil counts. Chest. 2016, 150:799-810. 10.1016/j.chest.2016.03.018

39. Yamada T, Sun Q, Zeibecoglou K, et al.: IL-3, IL-5, granulocyte-macrophage colony-stimulating factor receptor alpha-subunit, and common beta-subunit expression by peripheral leukocytes and blood dendritic cells. J Allergy Clin Immunol. 1998, 101:677-682. 10.1016/S0091-6749(98)70177-0

40. Lopez AF, Vadas MA, Woodcock JM, et al.: Interleukin-5, interleukin-3, and granulocyte-macrophage colony-stimulating factor cross-compete for binding to cell surface receptors on human eosinophils. J Biol Chem. 1991, 266:24741-24747.

41. FitzGerald JM, Bleecker ER, Nair P, et al.: Benralizumab, an anti-interleukin-5 receptor alpha monoclonal antibody, as add-on treatment for patients with severe, uncontrolled, eosinophilic asthma (CALIMA): a randomised, double-blind, placebo-controlled phase 3 trial. Lancet. 2016, 388:2128-2141. 10.1016/S01406736(16)31322-8

42. Bleecker ER, FitzGerald JM, Chanez P, et al.: Efficacy and safety of benralizumab for patients with severe asthma uncontrolled with high-dosage inhaled corticosteroids and long-acting beta2-agonists (SIROCCO): a randomised, multicentre, placebo-controlled phase 3 trial. Lancet. 2016, 388:2115-2127. 10.1016/S01406736(16)31324-1

43. Castro M, Wenzel SE, Bleecker ER, et al.: Benralizumab, an anti-interleukin 5 receptor alpha monoclonal antibody, versus placebo for uncontrolled eosinophilic asthma: a phase $2 \mathrm{~b}$ randomised dose-ranging study. Lancet Respir Med. 2014, 2:879-890. 10.1016/S2213-2600(14)70201-2

44. Nowak RM, Parker JM, Silverman RA, et al.: A randomized trial of benralizumab, an antiinterleukin 5 receptor alpha monoclonal antibody, after acute asthma. Am J Emerg Med. 2015, 33:14-20. 10.1016/j.ajem.2014.09.036

45. Park H-S, Kim M-K, Imai N, Nakanishi T, Adachi M, Ohta K, Tohda Y: A phase 2a study of benralizumab for patients with eosinophilic asthma in South Korea and Japan. Int Arch Allergy Immunol. 2016, 169:135-145. 10.1159/000444799

46. Goldman M, Hirsch I, Zangrilli JG, Newbold P, Xu X: The association between blood eosinophil count and benralizumab efficacy for patients with severe, uncontrolled asthma: subanalyses of the Phase III SIROCCO and CALIMA studies. Curr Med Res Opin. 2017, 33:1605-1613. 10.1080/03007995.2017.1347091

47. Nair P, Wenzel S, Rabe KF, et al.: Oral glucocorticoid-sparing effect of benralizumab in severe asthma . N Engl J Med. 2017, 376:2448-2458. 10.1056/NEJMoa1703501

48. Ferguson GT, FitzGerald JM, Bleecker ER, et al.: Benralizumab for patients with mild to moderate, persistent asthma (BISE): a randomised, double-blind, placebo-controlled, phase 3 trial. Lancet Respir Med. 2017, 5:568-576. 10.1016/S2213-2600(17)30190-X

49. Laviolette M, Gossage DL, Gauvreau G, et al.: Effects of benralizumab on airway eosinophils in asthmatic patients with sputum eosinophilia. J Allergy Clin Immunol. 2013, 132:1086-1096. 10.1016/j.jaci.2013.05.020

50. Pham TH, Damera G, Newbold P, Ranade K: Reductions in eosinophil biomarkers by benralizumab in patients with asthma. Respir Med. 2016, 111:21-29. 10.1016/j.rmed.2016.01.003 